\title{
Swedish experience of two dose vaccination programme aiming at eliminating measles, mumps, and rubella
}

\author{
MÁRGARETA BÖTTIGER, BRITH CHRISTENSON, VICTORIA ROMANUS, JOHN TARANGER, \\ ANNIKA STRANDELL
}

\begin{abstract}
In 1982 a two dose regimen was introduced in Sweden for the combined vaccination against measles, mumps, and rubella of children aged 18 months and 12 years. Since 1977 about half of the preschool children were vaccinated against measles annually, and since 1974 about $80 \%$ of 12 year old girls were vaccinated against rubella. During the period 1982 to $198590-93 \%$ of the eligible age cohorts of 18 month old children and $88-91 \%$ of the 12 year old children were immunised with the new combined vaccine. A study in 1982 of about 14018 month old children who were nearly all seronegative before vaccination showed that $96 \%$, $92 \%$, and $99 \%$ seroconverted against measles, mumps, and rubella, respectively. A second study was carried out in 1983 of 24712 year old children, of whom $11 \%$ lacked antibodies to measles, $27 \%$ to mumps, and $45 \%$ to rubella. This showed seroconversion in $\mathbf{8 2} \%$ and $80 \%$ against measles and mumps, respectively, and all children seroconverted against rubella. In the latest -study in 1985 of 49612 year olds $9 \%$ and $13 \%$ were seronegative against measles and mumps before vaccination, and $41 \%$ against rubella. Of these, $88 \%$ seroconverted to measles and $80 \%$ to mumps, and all converted to rubella when sera were tested by the haemolysis in gel method. After a neutralisation test against measles as well all children showed immunity to the disease.
\end{abstract}

- A low incidence of measles and declining figures for mumps and rubella were reported in 1984 to 1986 . An outbreak of rubella during 1985 affected mainly boys in age cohorts in which only the girls had been vaccinated during the 1970 s.

\section{Introduction}

In 1982 Sweden was the first country to introduce a two dose regimen for combined vaccination against measles, mumps, and

\footnotetext{
Department of Epidemiology, National Bacteriological Laboratory, S-105 21 Stockholm, Sweden

MARGARETA BÖTTIGER, MD, professor and director

BRITH CHRISTENSON, MD, acting assistant professor

VICTORIA ROMANUS, MD, assistant physician

Paediatric Outpatient Clinic, Västra Frölunda Hospital, Västra Frölunda, Sweden

JOHN TARANGER, MD, senior paediatrician

National Board of Education, 10642 Stockholm, Sweden ANNIKA STRANDELL, MD, chief medical officer

Correspondence to: Professor Böttiger.
}

rubella aimed at eliminating the three diseases. ${ }^{1}$ To do this at least $90 \%$ of the target population had to be vaccinated both at 18 months and at 12 years of age. ${ }^{2}$

General vaccination against measles had been introduced in Sweden in 1971, when vaccination was offered to children from the age of 18 months, but from the beginning the uptake rate was low. In 1981 reports from child health centres showed that $56 \%$ of all children aged 2-6 years (born between 1974 and 1978) had been vaccinated against measles. ${ }^{3}$ Vaccination against rubella had been offered to 12 year old girls since 1974 , and in 1980 the vaccination coverage was $84 \%$.

A mumps vaccine was registered in Sweden in the 1970s. There was no general vaccination, but the mumps vaccine was offered to children with sensorineural deafness.

The early experience with the new two dose vaccination programme has already been published. ${ }^{145}$ This paper describes the vaccination coverage, serological immunity, and morbidity among Swedish children four years after the introduction of the new vaccination programme.

\section{Subjects and methods}

\section{VACCINATION COVERAGE}

Preschool children in Sweden are immunised at child health centres. Since 1981 reports of the number of vaccinated and unvaccinated children per year of birth have been sent annually to the epidemiological department at the National Bacteriological Laboratory. All school health clinics report their vaccinations to the school health department of the National Board of Education.

\section{RESPONSE TO VACCINATION}

Blood samples were taken before and after vaccination from three groups. In 1982 about 140 children from four well baby clinics were studied. ${ }^{1}$ In 1983 a similar study was carried out on 24712 year old school children from four regions of Sweden, ${ }^{4}$ and in 1985-6 a similar vaccination study was carried out on 49612 year old children from four different regions.

The trivalent vaccine (MMR-vaccine, Merck, Sharp and Dohme) contained the Edmonston measles strain (strength $>4-8000$ median tissue culture infective dose), the Jeryl Lynn mumps strain ( $>100000$ median tissue culture infective dose), and the RA 27/3 rubella strain (>3-6000 median tissue culture infective dose).

Antibodies against all the viruses were tested by the haemolysis in gel method and assessed as previously described. ${ }^{15}$ In the 1982 study measles antibodies were first tested by the haemagglutination inhibition method but later 110 out of the samples were also tested by the haemolysis in gel method. In this age group the two methods gave similar results. ${ }^{5}$ In 1985 samples seronegative to measles by the haemolysis in gel method were also tested for neutralising antibodies. ${ }^{67}$ 
REPORTS ON MEASLES, MUMPS, AND RUBELLA, AND ON ADVERSE REACTIONS

The main surveillance system for these diseases is based on regular monthly reports from general practitioners. In addition, all laboratories report verified cases of rubella, measles, and mumps to the department of epidemiology at the National Bacteriological Laboratory. In Sweden it is obligatory to report severe and unexpected side effects of drugs and vaccinations to the adverse reactions advisory committee of the National Board of Health and Welfare.

\section{Results}

\section{VACCINATION COVERAGE}

The first age cohorts for which the two dose vaccination programme were recommended were 18 month old children born in 1981 and 12 year old children born in 1970: $91 \%$ of the infants and $88 \%$ of the older children received the trivalent MMR vaccine. This high coverage continued, and in 1985 the vaccination rate among eligible preschool children had increased to 93\%. Only one of 24 counties and 51 of 282 municipalities reported a vaccination rate of less than $90 \%$. During the school year $1985-692 \%$ of 12 year old school children were vaccinated. A vaccination rate of less than $90 \%$ was reported in four of 24 counties and 65 of 279 municipalities (information was not available from three municipalities).

\section{RESPONSE TO VACCINATION}

The serological study in 1982 showed that only one out of 140 prevaccination samples tested by haemagglutination inhibition and haemolysis in gel was seropositive against measles. One hundred and twenty six samples taken after vaccination from children who were not immune were tested by haemagglutination inhibition and 109 of them were also tested by haemolysis in gel. Seroconversion was observed in 121 (96\%). All samples negative by haemagglutination inhibition were also negative by the haemolysis in gel test.

For mumps only one of the 141 sera tested showed positive activity against mumps before vaccination; after vaccination 129 of $140(92 \%)$ had seroconverted.

For rubella two of the 142 samples taken before vaccination were seropositive. Seroconversion was seen in all but one of the 129 sera tested after vaccination.

The serological study of 12 year olds in 1983 showed that 28 out of the 247 sera $(11 \%)$ tested by the haemolysis in gel method lacked demonstrable antibodies against measles before vaccination. Table I shows that seroconversion occurred in 23 of $28(82 \%)$ of the initially seronegative children. With the neutralising antibody test three of the five seronegative samples after vaccination became seropositive. Sixty six out of 247 children (27\%) had no detectable antibodies against mumps virus in the prevaccination samples. The seroconversion rate was 53 of $66(80 \%)$. For rubella in the prevaccination samples $110(45 \%)$ were seronegative. They all seroconverted after vaccination.

The serological study of 12 year olds in 1985 showed that 64 of 496 (13\%) had no detectable antibodies against measles before vaccination. When assessed by the haemolysis in gel test 56 of $64(88 \%)$ of these children had seroconverted but when the neutralising antibody test was done all children became seropositive (table I). Thirteen per cent $(65$ of 496) of the children were susceptible to mumps before vaccination. Fifty three out of 65 children ( $80 \%$ ) seroconverted. For rubella $41 \%$ (201 of 496 ) of the school children were susceptible to rubella before vaccination. They all seroconverted.

Table II shows the prevalence of antibodies against measles, mumps, and

TABLE I Seroconversion against measles, mumps, and rubella. Figures for 1982 refer to infants, those for 1983 and 1985 to 12 year old children

\begin{tabular}{lccc}
\hline & \multicolumn{3}{c}{ No (\%) of children in whom seroconversion occurred } \\
\cline { 2 - 4 } Test used & 1982 & 1983 & 1985 \\
\hline Measles: & $121 / 126(96)$ & $23 / 28(82)$ & $56 / 64(88)$ \\
Haemolysis in gel & - & $26 / 28(92)$ & $64(100)$ \\
Neutralisation & $129 / 140(92)$ & $53 / 66(80)$ & $53 / 65(80)$ \\
$\begin{array}{l}\text { Mumps: } \\
\text { Haemolysis in gel }\end{array}$ & $129 / 130(99)$ & $110 / 110(100)$ & $201 / 201(100)$ \\
$\begin{array}{c}\text { Rubella: } \\
\text { Haemolysis in gel }\end{array}$ & & & \\
\hline
\end{tabular}

TABLE II-Estimated prevalence of antibodies against measles, mumps, and rubella after vaccination in all children, whether or not they were susceptible before vaccination. Figures for 1982 refer to infants, those for 1983 and 1985 to 12 year old children

\begin{tabular}{llll}
\hline & \multicolumn{3}{c}{ No (\%) of children with antibodies } \\
\cline { 2 - 4 } & $1982^{\star}$ & 1983 & 1985 \\
\hline Measles & $121 / 126(96)$ & $245+/ 247(99)$ & $496+/ 496(100)$ \\
Mumps & $129 / 140(92)$ & $234 / 247(95)$ & $484 / 496(98)$ \\
Rubella & $128 / 129(99)$ & $247 / 247(100)$ & $496 / 496(100)$ \\
\hline
\end{tabular}

*Owing to lack of enough serum from the infants not all postvaccination sera could be tested. As almost all infants were seronegative before vaccination seroconversion figures were similar to the prevalence figures.

†Including also a neutralising antibody test.

rubella before and after vaccination in the 12 year olds: all children are shown, including those immune before vaccination. The 18 month old children were almost all seronegative before vaccination so that seroconversion rates and prevalence rates were the same (table I).

\section{ADVERSE REACTIONS}

Table III summarises an analysis of 212 reports of adverse reactions after vaccination against measles, mumps, and rubella during 1982-4 that were sent to the Swedish Adverse Reaction Advisory Committee (J Taranger, B-E Wiholm, personal communication). During this period about 588300 children had been immunised. Most of the reported reactions were not serious, and in all but a few cases no symptoms remained after a follow up period of at least one year. The most serious reaction was a 12 year old girl who developed polyradiculitis and needed intensive care for some weeks.

TABLE III-Number of cases of adverse reactions to measles, mumps, and rubella vaccine reported to the Swedish Adverse Reactions Advisory Committee 1982-4. Figures in parentheses indicate those still symptomatic a year later

\begin{tabular}{lcc}
\hline \multicolumn{1}{c}{ Reaction } & \multicolumn{2}{c}{ Caused by the vaccine } \\
\cline { 2 - 3 } & Possible or probable & Unlikely or unassessable \\
\hline Rash or minor local signs & 62 & 0 \\
Minor systemic symptoms (for example, & 79 & 15 \\
$\quad$ fever) & $17(1)$ & 3 \\
Serious haematological abnormalities & $19(2)$ & $5(1)$ \\
Serious neurological sequelae & $7(2)$ & $4(4)$ \\
Other serious symptoms (for example, & & \\
$\quad$ anaphylaxis, arthritis) & & \\
\hline
\end{tabular}

Two years after the vaccination she still had difficulty with walking and micturition, as well as other symptoms. Another child 18 months old developed thrombocytopenic purpura and two years after vaccination still had a platelet count of less than $100 \times 10^{9} / 1$, though she had had no clinical symptoms during the past year. The remaining three patients with serious initial symptoms, which were probably caused by the vaccination, had only minor symptoms at follow up. Sixteen of the 19 patients with serious haematological abnormalities had thrombocytopenia, most of whom (14 of 16) were 18 month old children. Only seven of 25 children with potentially serious neurological symptoms were admitted to hospital.

\section{MORBIDITY}

Figure 1 shows the annual rates of measles, mumps, and rubella between 1969 and 1986 . The figure is based on clinical diagnoses reported monthly by the general practitioners.

There has been no large nationwide outbreak of measles since the introduction of measles vaccination in the early $1970 \mathrm{~s}$. The number of cases of measles reported during 1985 is the lowest annual figure so far. Reports of mumps and rubella are also declining, and the latest peaks in 1983-4 and 1985 are considerably lower than in the previous decade.

Figure 2 gives an estimate of the proportions of children immune and not 

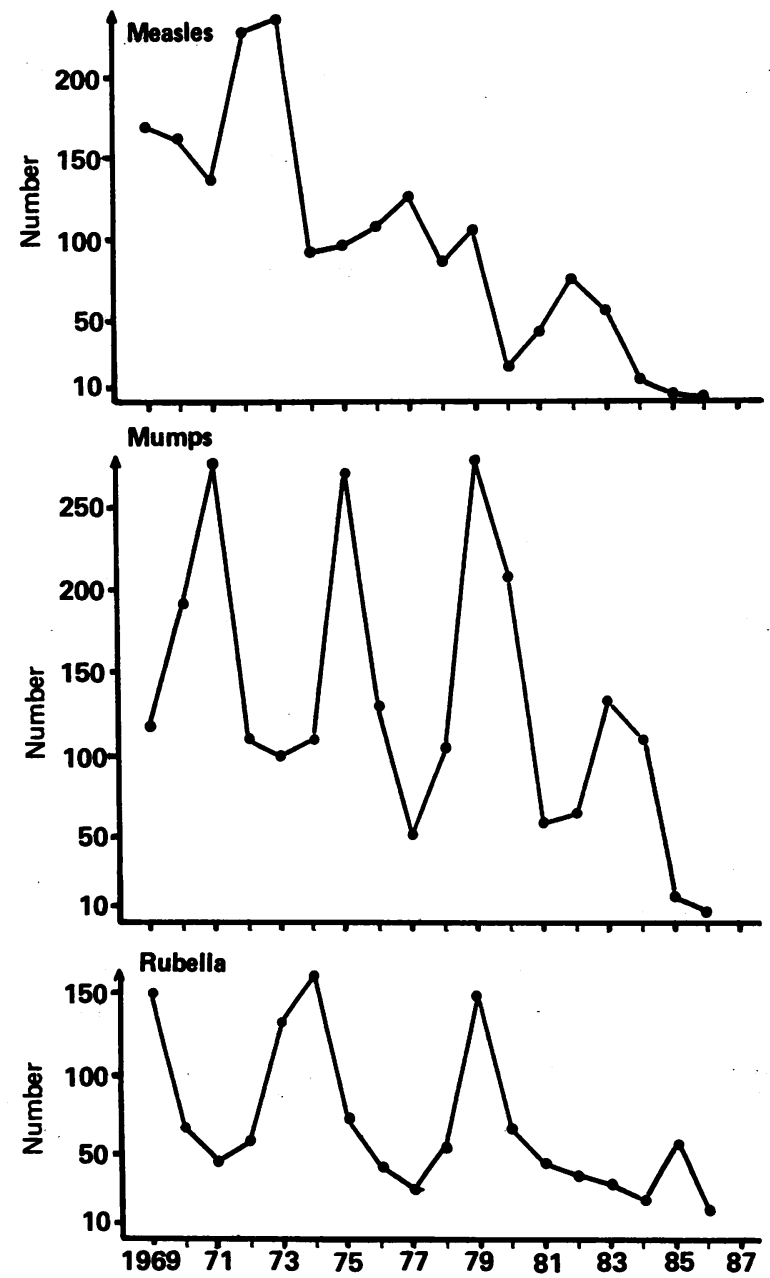

FIG 1-Annual case rate of measles, mumps, and rubella in Sweden 1969-86 according to general practitioners' monthly returns.

immune to measles, mumps, and rubella in 1985 . The shaded parts denote the children presumed to be susceptible. The interrupted line shows the circumstances before vaccination was introduced-that is, the natural course of the infections. The two open blocks indicate children immunised since 1982 .

The declining morbidity reflects the increasing degree of immunity. During the small outbreak of rubella in 1985 there were more cases among boys aged 15-24 years because in that age group only girls had been vaccinated (fig 3). No such age and sex differences were found for laboratory confirmed cases of measles or mumps during 1985.

\section{Discussion}

In Sweden a two dose vaccination programme against measles, mumps, and rubella was chosen to avoid a large number of adults being susceptible to these diseases. ${ }^{1}$ The primary goal-vaccination of at least $90 \%$ of Swedish children at the ages of 18 months and 12 years - has been reached nationally but not yet in each municipality, as is the case for diphtheria, tetanus, and polio. ${ }^{3}$

It is essential that the vaccine should give long term protectionif possible, lifelong immunity. We cannot know for many decades whether the Swedish two dose vaccination programme will reach this aim, but the first step is to show seroconversion in almost all children vaccinated. Seroconversion to measles increased from 82 to $96 \%$ when sera were tested by the haemolysis in gel method, but when the neutralisation antibody test was also done, this rose to almost $100 \%$. Seroconversion to rubella was almost $100 \%$, but to mumps only $80-92 \%$ (table I). The titres were lower after vaccination than after the naturally occurring diseases, ${ }^{4}$ but it remains to be seen if this will have any influence on long term protection. American studies of long term immunity after measles $\square$ vaccination have shown that although low antibody titres-or no antibodies at all-were found 16 years later in some subjects who $\frac{1}{\alpha}$ had initially undergone seroconversion, these subjects responded $\varrho$ quickly when revaccinated. ${ }^{8}$ This implies that they would have been protected against a wild measles virus. Serological immunity for $\stackrel{\varrho}{=}$ almost 20 years has also been reported after rubella vaccination. ${ }^{9}$

Although only about half the preschool children in Sweden were $\underset{\infty}{\mathbb{S}}$ vaccinated against measles during the second half of the 1970 s, there $m$ was a pronounced decrease in the incidence of measles (fig 1). After the two dose vaccination programme began in 1982 the decrease $\vec{F}$ continued to an all time low in 1985. The new programme- of vaccination both early and late during childhood-was designed to avoid the accumulation of a large number of non-immune $\overline{\bar{N}}$ adolescents, as occurred in the United States of America, where $\frac{\Phi}{\sigma}$ initially only preschool children were vaccinated. Ten to 15 years $\mathbb{\complement}$ later outbreaks of measles began to occur among adolescents. ${ }^{10} 11 \mathrm{\omega}$ The incidence of measles decreased in the USA until 1983 but since $\vec{\circ}$ then there has been an annual increase. The preliminary figure for $:$ 1986 is about four times higher than the all time low value of $\vec{\omega}$ $1983 .{ }^{12}{ }^{13} \mathrm{~A}$ similar development has also been reported from Canada $\stackrel{\circ}{\circ}$ (which also has a one dose preschool vaccination programme against measles); the number of cases during the first third of 1986 was about 20 times higher than in the same period of $1985 .{ }^{14}$ In the USA $O F$ outbreaks of measles during 1986 not only occurred among $\dot{ }$ adolescents, but also among preschool children, most of whom had ${ }^{\circ}$ not been vaccinated..$^{12}{ }^{13}$ Of the cases reported in the USA during the first half of 1986 , however, $42 \cdot 2 \%$ occurred among those classified $\vec{N}$ as adequately vaccinated. A second vaccination ought to be considered if the aim is to eliminate measles.

As far as mumps is concerned, the expected outbreak during $\vec{A}$
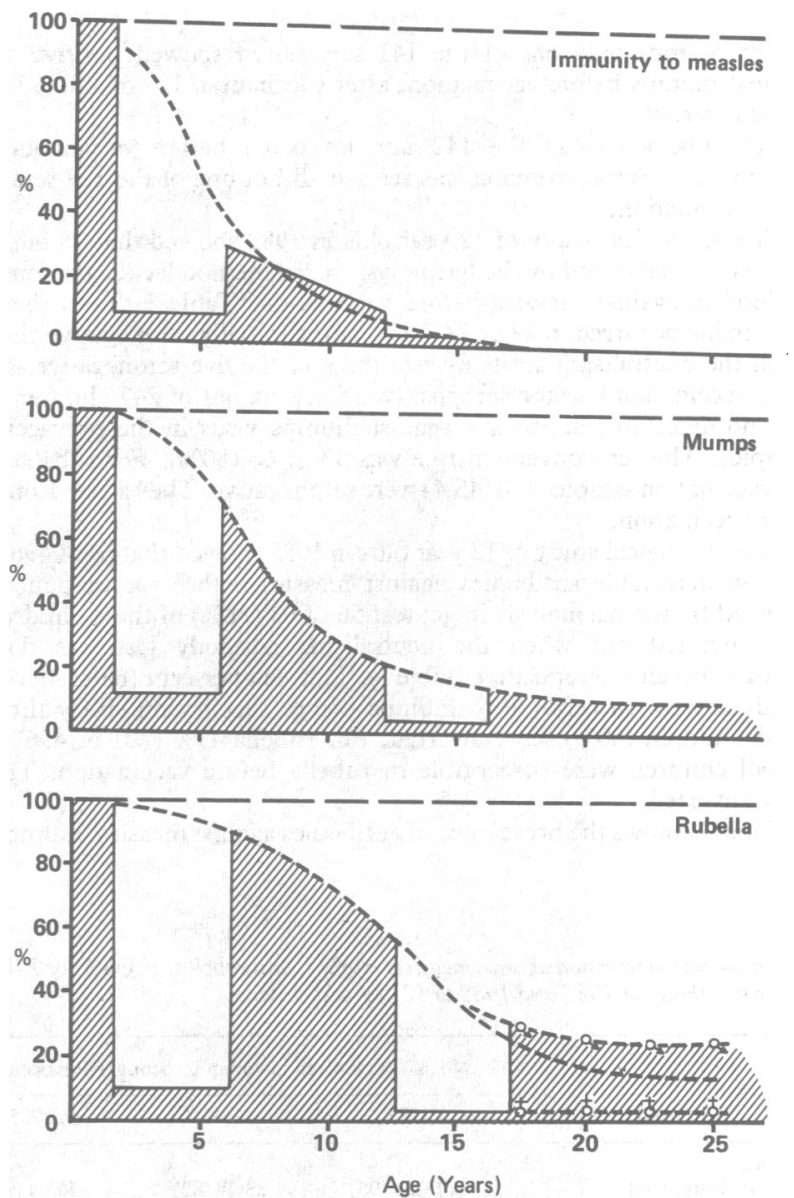

FIG 2 -Calculated proportions of Swedish children immune and not immune to measles, mumps, and rubella in 1986 . Shaded parts denote children presumed to $?$ be susceptible, interrupted lines indicate estimated morbidity curves before vaccination. 

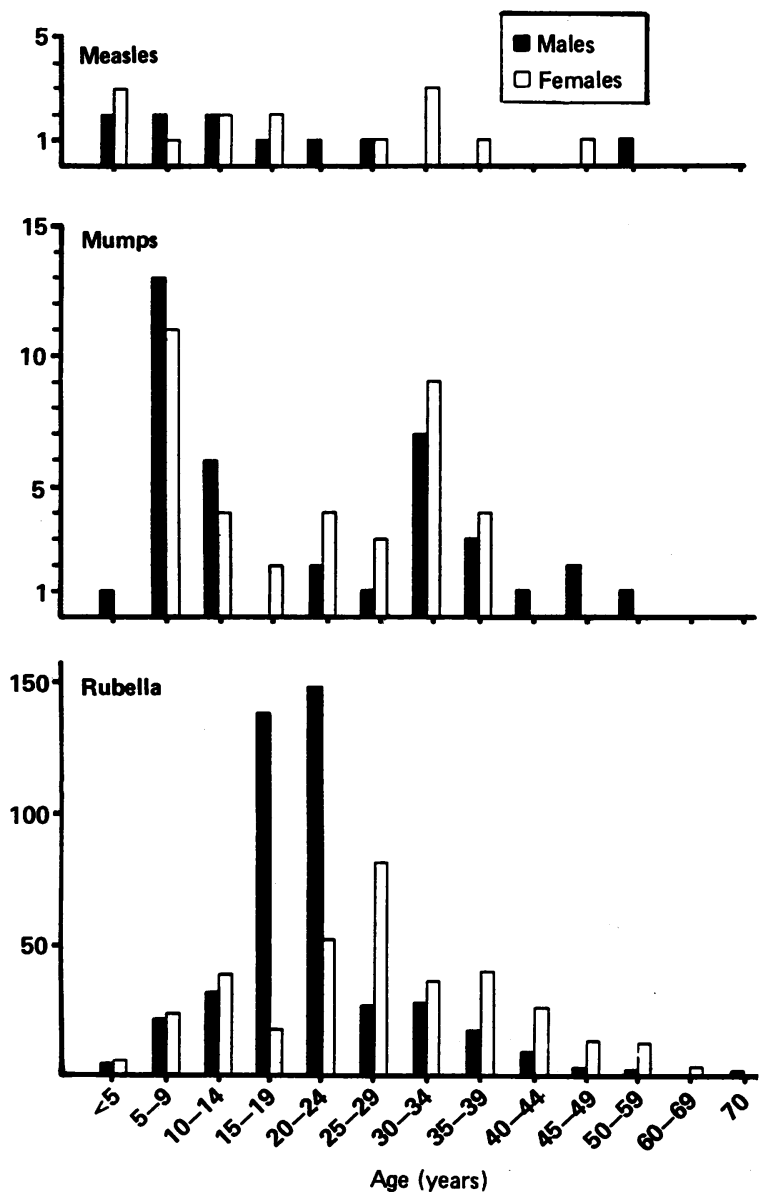

FIG 3-Age and sex distribution of serologically confirmed cases of measles, mumps, and rubella in Sweden during 1985.
1983-4 was moderate, which might be an early effect of vaccination despite the fact that most of the children who got the disease were in the 5-9 years age group and had not yet been immunised. Morbidity from rubella did not change until the beginning of the 1980s (fig 1), although 12 year old girls had been vaccinated against the disease since 1974. Sex and age analysis of serologically verified cases during the outbreak in 1985 indicated, however, that the vaccination of schoolgirls had had epidemiological effects from the beginning.

Nevertheless, all national vaccination programmes that interfere with the natural progression of a virus must be evaluated continuously to prevent failures.

\section{References}

1 Christenson B, Böttiger M, Heller L. Mass vaccination programme aimed at eradicating measles, mumps, and rubella in Sweden: first experience. BrMed f 1983;287:389.

2 Rabo E, Taranger J. Scandinavian model for eliminating measles, mumps, and rubella. BrMed $f$ 1984;289:1402-4.

3 Romanus V, Jonsell R, Böttiger M, Alvin A, Sandzelius G. Vaccinationstatus hos svenska förkolebarn. Läkartidningen 1982;79:2863-5.

4 Böttiger M, Christenson B, Taranger J, Bergman M. Mass vaccination programme aimed at eradicating measles, mumps and rubella in Sweden: vaccination of schoolchildren. Vaccine 1985;3:113-6.

5 Christenson B, Böttiger M. Vaccination against measles, mumps and rubella (MMR): a comparison between the antibody responses at the ages of 18 months and 12 years and between different methods of antibody titration. $\mathcal{F}$ Biol Stand 1985;13:167-72.

6 Strannegård Ö, Grillner L, Lindberg JM. Haemolysis-in-gel test, the demonstration of antibodies to rubella virus. $\mathcal{F}$ Clin Microbiol 1975;1:491.

7 Kenny MT, Albright KL, Sanderson RP. Microneutralization test for the determination of mumps antibody in vero cells. Applied Microbiology 1970;3:371-3.

8 Krugman S. Further-attenuated measles vaccine: characteristics and use. Reo Infect Dis 1983;5:477-81

9 O'Shea S, Best J, Banatvala JE, Marshall WC, Dudgeon JA. Persistence of rubella antibody 8-18 years after vaccination. BrMed $\mathcal{J} 1984 ; 288: 1043$.

10 Centers for Disease Control. Measles on college campuses-United States. MMWR 1985;34: 445-9.

11 Gustafson TL, Lievens AW, Brunell PA, Moellenberg RG, Buttery CMG, Sehulster LM. Measles outbreak in a fully immunized secondary-school population. N Engl f Med 1987;316:771-4. 12 Centers for Disease Control. Measles-United States. First 26 weeks, 1986. MMWR 1986;35 525-8.

13 Centers for Disease Control. Measles-United States. First 26 weeks, 1986. MMWR 1986;35 533.

14 Centers for Disease Control. Update: measles-Canada, 1986. MMWR 1986;35:331-3.

(Accepted 10 July 1987)

\section{MATERIA NON MEDICA}

\section{Après nous...}

"Fermé en hiver," said the notice; but on a warm July evening there were cowbells in the Alpine pastures and the single track road climbed the mountainside among snowless firs. The $\mathrm{Col}$ du $\mathrm{Coq}$ begins near the monastery of Chartreuse, rises higher than Ben Nevis, and then twists down a cliff face on its way towards Grenoble. As we crawled upwards in second gear we wondered why the Parti Communiste Francais had recently painted neat white hammer and sickle emblems at intervals in the middle of the road. Then we saw the tiny gravelly laybys filled with darkened Renault vans and the cardboard arrow, sponsored by Peugeot, delineating what was presumably one of the more demanding stages of the world's greatest cycle race.

Next morning knots of people gathered at the hairpin bends. Two armed policemen closed the road to cars but allowed a trio of elderly cyclists to pedal doggedly upwards. We feared a Horatius-like confrontation with the descending horde but soon a police car swept downwards and a sergeant gesticulated, “... personne ... même les bicyclistes...." His grey headed superior gazed, silent and Godfatherly, from the back seat.

After a pause two advertising lorries ("Coca-Cola, c'est ça!") rushed past, followed by a vintage fire engine with a Michelin man sitting on the ladder. Groups of cars with stickers in primary colours almost bumped one another as they hurtled around the bends. Half a dozen go karts careered along with giant bottles of lavatory cleaner attached to them. A car advertising fly killer was accompanied by another with a giant insect expiring supine on its roof. A motorcycle combination raced down the hill on two wheels with a massive beer bottle in the sidecar. From two cars in the shape of the train grande vitesse handfuls of paper hats were hurled at the spectators. Vans stopped briefly to sell souvenirs. Another Michelin man stood on the saddle of his motorbike to wave to the crowd. A bright yellow car zoomed along with an identical full size car upside down on its roof. Overhead a helicopter zigzagged towards us. On the road a long gap was followed by the international press, carloads of gendarmes, the headlights of police motorcyclists, and then the television cars.

The competitors themselves appeared preoccupied, perhaps feeling that as mere cyclists they were rather an anticlimax.-JAMES OWEN DRIFE, Leicester.

What is the customary time between a patient being infected by Plasmodium falciparum and symptoms of malaria appearing?

About $90 \%$ of patients with falciparum malaria transmitted by mosquitoes develop symptoms within one month, the commonest incubation period being 11 to 14 days. The remaining $10 \%$ nearly all present within six months with infections. ${ }^{1} \mathrm{~A}$ few patients who are taking a prophylactic drug to which the malaria parasites are only partially sensitive show symptoms only after they stop taking the drug. ${ }^{2}$ Falciparum malaria probably never presents less than six days after mosquito transmission since there must be sufficient time for the development of exoerythrocytic schizonts in the liver before invasion of red cells and it is only as infection in the red cells builds up that symptoms occur. Malaria transmitted by syringe or blood transfusion might have a shorter incubation period if sufficient parasites are injected. ${ }^{3}$ G B WYATT, senior lecturer in tropical medicine, Liverpool.

1 Bruce-Chwatt LJ. Imported malaria: an uninvited guest. Br Med Bull 1982;38:179-85.

2 Quinn.TC, Strickland GT. Clinical manifestations of malaria. In: Strickland GT, ed. Malaria. London: WB Saunders, 1986: 127-70.

3 Garnham PCC. Malaria in its various vertebrate hosts. In: Malaria. Vol 1. Epidemiology, chemotherapy, morphology and metabolism. New York: Academic Press, 1980:95-144. 